\title{
Ectopic expression of the serine protease inhibitor PI9 modulates death receptor-mediated apoptosis
}

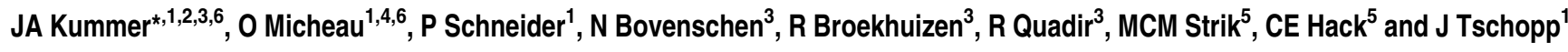

Apoptosis is a highly controlled process, whose triggering is associated with the activation of caspases. Apoptosis can be induced via a subgroup of the tumor necrosis factor (TNF) receptor superfamily, which recruit and activate pro-caspase-8 and 10. Regulation of apoptosis is achieved by several inhibitors, including C-FLICE-inhibitory protein, which prevents apoptosis by inhibiting the pro-apoptotic activation of upstream caspases. Here we show that the human intracellular serine protease inhibitor (serpin), protease inhibitor 9 (PI9), inhibits TNF-, TNF-related apoptosis-inducing ligand- and Fas ligand-mediated apoptosis in certain TNF-sensitive cell lines. The reactive center P1 residue of PI9 was required for this inhibition since PI9 harboring a Glu $\rightarrow$ Ala mutation in its reactive center failed to impair death receptor-induced cell death. This suggests a classical serpin-protease interaction. Indeed, PI9 inhibited apoptotic death by directly interacting with the intermediate active forms of caspase-8 and -10 . This indicates that PI9 can regulate pro-apoptotic apical caspases.

Cell Death and Differentiation (2007) 14, 1486-1496; doi:10.1038/sj.cdd.4402152; published online 4 May 2007

Apoptosis is a highly controlled process, whose triggering is mainly associated with the activation of proteolytic enzymes. $^{1,2}$ In the immune system, apoptotic death in target cells is mediated by cytotoxic lymphocytes (CL) including natural killer cells and cytotoxic T lymphocytes. These cells induce apoptosis via two different pathways: (a) the degranulation pathway and (b) a membrane receptor-ligand interaction involving members of the tumor necrosis family (TNF). ${ }^{2,3}$ In both pathways, activation of protease cascades plays an essential role in apoptotic death.

Granules of CL contain several serine proteases called granzymes, of which granzyme $B$ is the most important. Granzyme B possesses a unique Asp-ase activity and, upon entering the target cell, cleaves and activates pro-caspase-3 and other substrates to initiate apoptotic death. Target cell death can also be induced by members of the TNF family, such as membrane-bound Fas ligand (FasL) on the CL that interacts with its receptor Fas. Soluble- and membrane-bound TNF and TNF-related apoptosis-inducing ligand (TRAIL) also mediate death via their respective receptors, TNF receptor (TNF-R1) and TRAIL receptors (TRAIL-R1 and -R2). ${ }^{4}$ Activation of these receptors lead to recruitment of the adaptor molecule, Fas-associated death domain (FADD). ${ }^{5,6}$ The death effector domain (DED) of FADD then recruits procaspase-8 and procaspase-10 via homotypic interaction with the DEDs in these caspases. Ligand, receptor, adaptor proteins and caspases form the death-inducing signaling complex (DISC). The high local concentration of procaspases promotes auto-activation and release into the cytosol triggering subsequent cleavage of downstream effector caspases (caspase-3, -6 and -7) leading to apoptotic death. Altogether, the induction and execution of apoptosis by CLs is mediated both by cysteine proteases, such as caspases, and by serine proteases, such as granzymes.

Activation of apoptotic proteases within the cell is tightly regulated. A central regulator of the death receptor-induced apoptosis is the protein C-FLICE-inhibitory protein (FLIP), which exists as two splice variants: FLIP $_{S}$ (short form) and FLIP $_{\mathrm{L}}$ (long form). FLIP $\mathrm{L}_{\mathrm{L}}$ resembles caspase-8, but is inactive due to a substitution of the active site cysteine for a tyrosine. Upon receptor engagement both caspase-8 and FLIP are recruited to the DISC, leading to partial caspase-8 processing and resistance to death receptor-induced apoptosis. ${ }^{7}$

Another inhibitor of the death receptor-induced apoptosis is the cowpox serine protease inhibitor (serpin) cytokineresponse modifier-A (CrmA). CrmA was discovered by virtue of its property to inhibit active caspase- 1 and thus preventing pro-IL-1 $\beta$ conversion and secretion. However, CrmA is also a very potent inhibitor of Fas-, TNF- and TRAIL-mediated apoptosis $^{8,9}$ as it inhibits active caspase- $-{ }^{8}$ CrmA is a member of a large subfamily of serpins that are mainly localized intracellularly. As their main function is to inhibit activated proteases, intracellular serpins likely serve to regulate intracellular protease activity. Indeed human intracellular serpins have been postulated to protect cells against unwanted carry over of serine proteases from cytoplasmic

\footnotetext{
${ }^{1}$ Department of Biochemistry, University of Lausanne, BIL Biomedical Research Center, Chemin des Boveresses 155, CH-1066 Epalinges, Switzerland; ${ }^{2}$ Department of Pathology, VU University Medical Center, Amsterdam, The Netherlands; ${ }^{3}$ Department of Pathology, University Medical Center Utrecht, Utrecht, The Netherlands; ${ }^{4}$ INSERM, U517, University of Bourgogne, Dijon, F-21000, France and ${ }^{5}$ Department of Immunopathology, Sanquin Research at CLB and Landsteiner Laboratory, Academical Medical Center, Amsterdam, The Netherlands

*Corresponding author: JA Kummer, Department of Pathology (H04.312), University Medical Center Utrecht, PO Box 85500, 3508 GA Utrecht, The Netherlands. Tel: 0031-30-2506565; Fax: 00-31-30-2544990; E-mail: j.a.kummer@umcutrecht.nl

${ }^{6}$ Both these authors have contributed equally to this article.

Keywords: apoptosis; caspase; protease inhibitor 9; serpin; sarcoma

Abbreviations: $C L$, cytotoxic lymphocyte; CrmA, cytokine-response modifier-A; DED, death effector domain; DISC, death-inducing signaling complex; FADD, Fasassociated death domain; FLIP, FLICE-inhibitory protein; serpin, serine protease inhibitor; TNF, tumor necrosis factor; TRAIL, TNF-related apoptosis-inducing ligand. Received 13.3.07; accepted 15.3.07; Edited by RA Knight; published online 04.5.07
} 
granules and are able to modify apoptotic pathways as well (reviewed in ${ }^{10}$ ).

Some years ago, the serpin PI9 has been identified as the human homolog of $\mathrm{CrmA} .{ }^{11}$ The reactive center of PI9 shows $54 \%$ identity with that of CrmA, and contains a Glu at the P1 and a Cys at the $\mathrm{P} 1^{\prime}$ position. Although granzyme $\mathrm{B}$ preferentially cleaves substrates with Asp rather than Glu at the $\mathrm{P} 1$ position, PI9 inhibits granzyme $\mathrm{B}$ at physiological concentrations. It has been proposed that PI9 protects CLs against death induced by their own, misdirected granzyme B. $^{12,13}$ Like CrmA, PI9 displays probably cross-class inhibition by inhibition of caspases. However, the few studies that have investigated the effect of PI9 on caspase proteolytic activity generated conflicting results. It has been shown that PI9 inhibits active caspase- 1 in vitro ${ }^{14,15}$ and, to a lesser extent, caspase-4 and $-8 .{ }^{14}$ In the latter study, non-SDS-stable complexes were detected between PI9 and the P10/20 of caspase-1 and -4 . Another report studied the functional significance of the interaction of PI9 with caspase-1 in human smooth muscle cell lysates. ${ }^{15}$ In contrast, others could not show any influence of PI9 in Fas-triggered, caspase-8mediated, apoptotic cell death using transfected Jurkat cells. $^{12,16}$

In the present study, we investigated the role of PI9 in death receptor-mediated apoptosis in several tumor cell lines. Using a retroviral approach, which enables moderate expression of PI9, we demonstrate that PI9 has the ability to inhibit apoptosis mediated by TNF, TRAIL and FasL in several sarcoma cell lines. PI9 inhibits cell death by binding to the intermediate active forms of caspase-8 (p43/41) and caspase-10 (p47/43) thereby preventing further activation of the downstream target caspase-3 and execution of apoptosis.

\section{Results}

PI9 inhibits TNF-, TRAIL- and FasL-mediated apoptosis in the fibrosarcoma cell line HT1080. As a model for TNFmediated cell death, the fibrosarcoma cell line HT1080 was used in which an undegradable form of the NF- $\kappa$ B inhibitor I$\kappa \mathrm{B} \alpha$ is stably expressed (HT1080-I- $\kappa \mathrm{B}$ ) (Figure 1a, bottom panel). Cells expressing $\mathrm{I}-\kappa \mathrm{Bm}$ ut are sensitive to TNFmediated apoptosis (Figure 1b), whereas the parental cell line is not (results not shown, ${ }^{17}$ ). In this model, TNF-induced apoptosis is entirely dependent on caspase activation, as low concentrations of the pancaspase inhibitor zVAD-fmk $(5 \mu \mathrm{M})$ inhibited the apoptotic process. ${ }^{17}$ HT1080wt and HT1080-I$\kappa$ Bmut do not express PI9 endogenously (Figure 1a, top panel), but after retroviral infection these cell lines expressed equal levels of PI9 or inactive PI9 E322A. TNF-mediated apoptotic death was completely abrogated by PI9 comparable to that achieved by expression of FLIP (Figure 1b). The PI9 E322A mutant, however, was inefficient in inhibiting TNF-induced apoptosis (Figure 1b). PI9 E322A contains a point mutation at the $P_{1}$ position in the reactive site loop resulting in the replacement of the $P_{1}$ Glu by an alanine preventing the covalent interaction and the subsequent inhibition of the target protease. ${ }^{18}$ Similarly, PI9 but not PI9 E322A inhibited TRAIL- and FasL-mediated apoptosis (Figure 1c and d). In the case of FasL, PI9 was even more effective than FLIP $\mathrm{L}$ to prevent apoptosis. We also investigated if PI9 was able to modify cell death in the TNF-resistant parent line HT1080wt. Also here, PI9 inhibited TRAIL- as well as FasL-mediated (Figure 1e) apoptosis.

Substitution of the P1-amino acid abolishes the inhibitory capacity of serpins and frequently converts them into substrates, which are rapidly cleaved in their reactive site loops by non-target proteases. ${ }^{18}$ Indeed, expression of PI9 E322A in non-stimulated HT1080-I- $\kappa$ B showed a spontaneous cleavage product at $38 \mathrm{kD}$ in addition to the uncleaved serpin (Figure 1a, lane 5). The rate of cleavage did not increase during apoptosis (Figure 3, right panel), suggesting that mutated PI9 is not cleaved by a caspase but by another non-target protease.

No differences in surface expression of death receptors Fas and TNFR1 were observed between PI9- and PI9 E322Ainfected cells (data not shown). Altogether, these results show that the Glu residue at the P1 position of PI9 is crucial for its cell death inhibitory activity and strongly suggests that a protease with affinity for this amino acid is the target of PI9.

PI9 inhibits caspase-3 and PARP processing but not caspase- 8 and $\mathbf{- 1 0}$ processing. The observation that PI9 inhibits TNF-, Fas- and TRAIL-induced apoptosis in a similar fashion suggested that its target is a common protease involved in death receptor signaling. This prompted us to investigate in more detail which caspase might be affected by PI9 in HT1080 I- $\kappa$ B cells. PI9wt, PI9 E322A and mockinfected HT1080-I- $\kappa$ B cells were stimulated with TRAIL for different period of time, and the cell lysates were analyzed by Western blot to determine at which level the apoptotic pathway is inhibited by PI9. As expected, the upstream caspase- 8 and -10 , the downstream caspase- 6 and -3 , and the caspase- 3 substrate PARP were all cleaved in the TRAIL-sensitive mock-infected HT1080-I- $\kappa$ B cells 3 and $6 \mathrm{~h}$ after TRAIL stimulation (Figure 2). In cells expressing PI9wt, caspase-6, -3 and PARP were not cleaved, in line with the observation that PI9 completely protects these cells from TRAIL-induced death. In contrast, caspase-6, -3 and PARP were still cleaved in cells expressing the $P_{1}$ mutant, but at somewhat reduced levels when compared to mock-infected cells. This demonstrates that an intact reaction site loop is required to mediate the full anti-apoptotic effects of PI9 (Figure 2). We cannot rule out that the mutant retains some residual activity, which is however insufficient to protect the cells.

The p43/41 fragment of pro-caspase- 8 was still detectable in PI9-expressing cells after 3 and $6 \mathrm{~h}$ after stimulation, although at reduced levels compared to mock-infected cells. In the case of caspase-10 only a very faint $\mathrm{p} 47 / 43$ band was detected in PI9-expressing cells at $3 \mathrm{~h}$. Longer exposure also revealed this intermediate fragment at $6 \mathrm{~h}$ in these cells (result not shown). These results indicated that, while blocking the cleavage of the downstream caspases, PI9 only partially prevented caspase-8 or -10 processing, suggesting that PI9 inhibited the apoptotic pathway between the upstream caspase-8/-10 and the effector caspase- 6 and -3 .

PI9 interacts directly with active caspase-8 and $\mathbf{- 1 0}$. To identify the target protease of PI9 that is activated in 
a
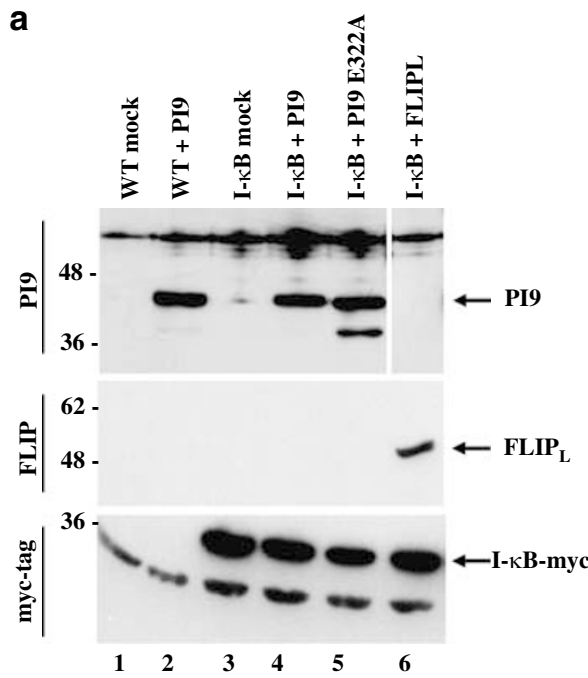

C

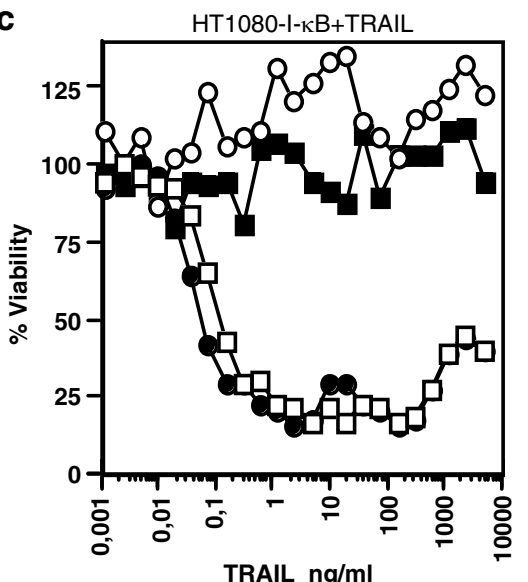

b

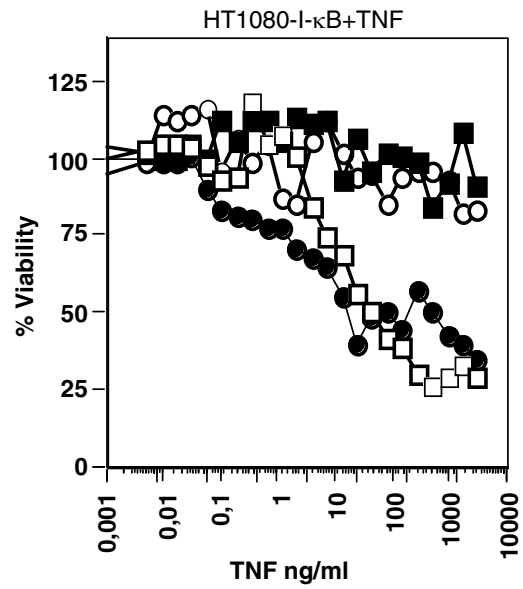

d

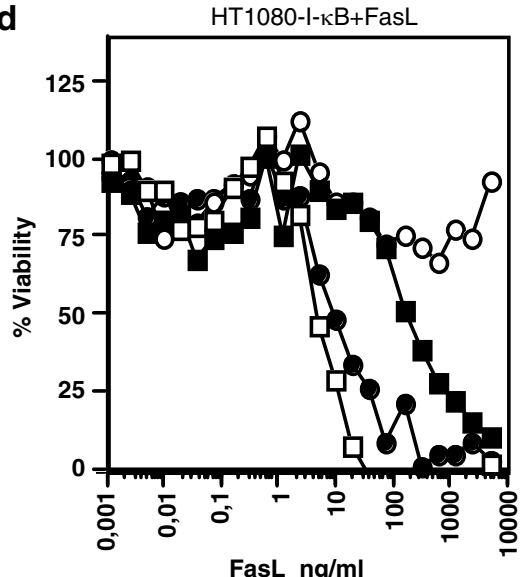

e
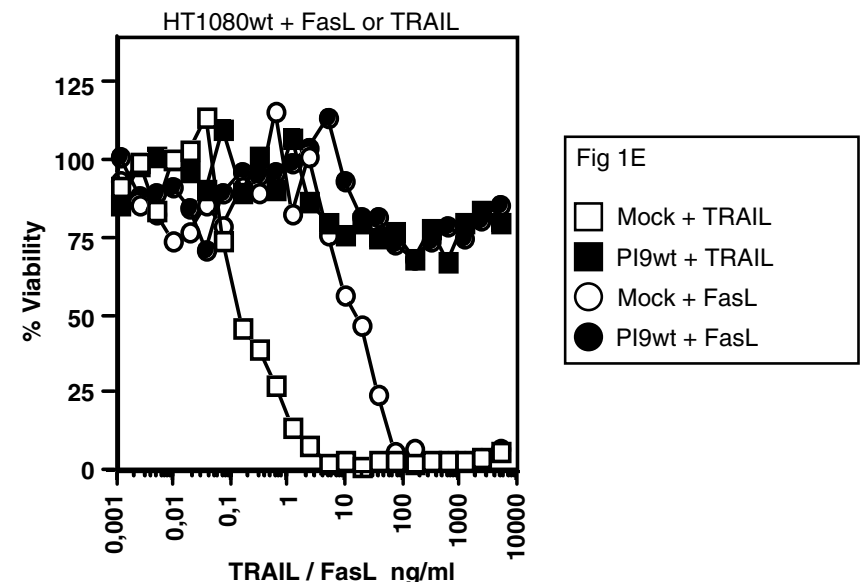

Figure 1 PI9 but not its active site mutant protects HT1080-I- $\kappa$ B from TNF-, TRAIL- and FasL-mediated apoptosis. (a) The HT1080 fibrosarcoma line was infected with an empty retroviral vector (mock) or a vector encoding PI9. The TNF-sensitive, HT1080 mutant cell line, I- $\kappa$ Bmut (stably transfected with a myc-tagged, non-degradable version of $\mathrm{I}-\kappa \mathrm{B} \alpha$ ) was infected with an empty vector (mock) or vectors containing PI9wt, PI9 E322A or FLIPL. After selection with puromycin, stably transformed cell populations were tested for protein expression by Western blot using antibodies against PI9, FLIP or the myc-tag. (b and $\mathbf{d}$ ) The cell lines were treated with the indicated concentration of soluble forms of TNF (b), TRAIL (c) and FasL (d). Cell viability was assessed by methylene blue staining. In (e), the TNF-resistant cell line HT1080wt transformed with PI9 was treated with TRAIL and FasL 
response to the apoptotic stimulus, we used monoclonal antibody (mAb) PI9-101 that specifically recognizes the native or complexed PI9 protein, in order to perform immunoprecipitation experiments. ${ }^{19}$ PI9wt and PI9 E322A HT1080-I- $\kappa$ B cells were stimulated for $0 \mathrm{~min}, 15 \mathrm{~min}, 1 \mathrm{~h}$ and $5 \mathrm{~h}$ with FasL before immunoprecipitation with mAb PI9-101. Western blot of whole-cell extracts showed a similar pattern as that seen in TRAIL-treated cells. In both PI9wt and PI9 E322A expressing cells, caspase-8 and -10 activation/ consumption occurred $5 \mathrm{~h}$ after FasL stimulation (Figure 3, right panel), although only PI9 E322A cells activated caspase-3 and died (Figure 1d, data not shown).

Both PI9wt and PI9 E322A were equally well immunoprecipitated from the cell lysates, whereas Sepharose beads coated with an irrelevant isotype-matched mAb did not precipitate PI9 (Figure 3, left panel). After $5 \mathrm{~h}$ of FasL stimulation, active caspase-8 (p43/41) and -10 (p47/43) proteins co-precipitated with PI9wt. In the case of caspase10 , an interaction with PI9wt could be demonstrated already after $15 \mathrm{~min}$. This interaction is dependent on the P1 Glu residue as caspase- 8 or -10 was not co-immunoprecipitated with PI9 E322A (Figure 3, left panel). Furthermore, no interaction with the active $p 18 / 10$ caspase- 8 or -10 fragments could be observed with PI9wt (results not shown). DISC components such as Fas or the adaptor proteins FADD or RIP were not co-precipitated with PI9 (Figure 3, left panel). In addition, no binding of PI9 to caspase-3 or -4 was detected (result not shown).

PI9 modulates TNF-ligand-mediated cytotoxicity at physiologically relevant concentrations. Our results clearly show that PI9 can inhibit death receptor-mediated apoptosis in HT1080-I- $\kappa \mathrm{B}$ and wt cells. The question arose if the inhibition observed is due to high, non-physiological, PI9 protein levels. Therefore, three HT1080-I- $\kappa$ B cell populations that express different levels of PI9 antigen (HT1080-I- $\kappa$ B-

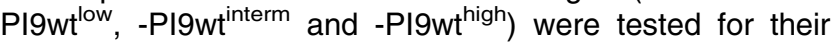
sensitivity to TNF ligand, TRAIL and FasL. The concentration of PI9 antigen, varied between $3.9 \mathrm{ng}$ PI9 (PI9wt ${ }^{\text {low }}$ ) and $29.2 \mathrm{ng}\left(\mathrm{PI} \mathrm{wt}^{\text {puro }}\right.$ ) per milligram total protein (Figure $\left.4 \mathrm{a}\right)$. A dose-dependent relationship between the level of PI9 antigen and the protection against cell death was observed for FasL (Figure 4a, left panel) and TNF (right panel). HT1080-I- $\kappa \mathrm{B}-$ $\mathrm{PIOwt}^{\text {puro }}$ again showed a near complete protection (around 90\%) for both TNF and FasL. Interestingly, cells expressing the lowest amount of PI9 (PI9wt ${ }^{\text {low }}$ ) still showed 18\% (FasL) and $24 \%$ (TNF) protection compared to the control cells. Similar results were obtained for TRAIL-mediated apoptosis (not shown). The sensitivity of the HT1080-I- $\kappa \mathrm{B}-\mathrm{PI9}$ E322A $\mathrm{A}^{\text {high }}$ was comparable to the mock-infected cells (Figure4a, data not shown).

In normal tissues, PI9 is highly expressed by lymphocytes, dendritic cells and endothelial cells. ${ }^{20}$ To compare the endogenous level of PI9 expression in these cells with the transfected cell lines used, cells were injected separately in human tonsillar tissues and processed for immunohistochemistry. Sections of these tonsils were stained for PI9 using mAb PI9-17 and developed with 3,3'-diaminobenzidine (DAB) for only $30 \mathrm{~s}$ (normal incubation time is $5-10 \mathrm{~min}$ ) to ensure that the staining curve lies within its linear phase not reaching its plateau. As expected, a gradual increase in staining intensity is observed from HT1080-I- $\kappa$ B-PI9wt ${ }^{\text {low }}$ (Figure $4 \mathrm{~b}$ ), in which the PI9 staining is hardly detectable, to PI9wt ${ }^{\text {puro }}$ (Figure $4 \mathrm{e}$ ), in which a strong staining is observed (see arrows). Under these conditions, PI9 staining intensity in both endothelial (Figure 4f, arrowhead) and dendritic cells (Figure 4g, arrowhead) was as strong as that of the HT1080-I- $\kappa$ B-PI9wt ${ }^{\text {high }}$, indicating that the range of PI9 level expression obtained by viral infection in our system is comparable to what can be observed in primary cells. These results were confirmed by direct quantification of PI9 levels by ELISA. Cultured primary endothelial cells (HUVEC) expressed two- to threefold more of the endogenous PI9 $(44.5 \pm 3.0 \quad(t=0 \mathrm{~h}), 53.0 \pm 5.4$ $(t=24 \mathrm{~h})$ and $81.5 \pm 6.1(t=48 \mathrm{~h})$ nanogram PI9 per milligram total protein than did HT1080-I- $\kappa \mathrm{B}-\mathrm{PI} \mathrm{wt}^{\text {puro }}$ cells with transduced PI9 (29.2 ng/mg).

PI9 modulation of TNF-ligand-mediated cytotoxicity is dependent on the cell type. In order to investigate whether the effect of PI9 could be observed in other tumor cell lines, PI9 and PI9 E322A were expressed in three additional TNFsensitive cell lines (the naturally TNF-sensitive fibrosarcoma WEHI 164, the modified carcinoma cell lines HCT116-I$\kappa$ Bmut $^{21}$ and MCF-7-I- $\kappa$ Bmut $^{22}$ ) and the TNF-resistant, FasL-sensitive Jurkat T-cell line JA3. None of these cell lines did express endogenous PI9. WEHI 164 cells infected with a PI9wt-containing retrovirus showed approximately $50 \%$ protection for both TNF- and FasL-mediated apoptosis compared to the mock- and PI9 E322A-infected cells (Figure 5a). Although complete protection could not be observed, the PI9 protein expression level in the WEHI 164$\mathrm{PI9wt}$ is much lower than that achieved in HT1080-I- $\kappa \mathrm{B}$ $\mathrm{PI9wt}^{\text {low }}\left(\mathrm{I}-\kappa \mathrm{B}-\mathrm{PI} 9^{\text {low }}\right.$, see inset Figure 5a). PI9, however, was not able to inhibit TNF- or FasL-mediated apoptosis in HCT116-I- $\kappa$ Bmut (Figure 5b), MCF-7-I- $\kappa$ Bmut (not shown) or Jurkat cell lines (Figure 5c). This could not fully be explained

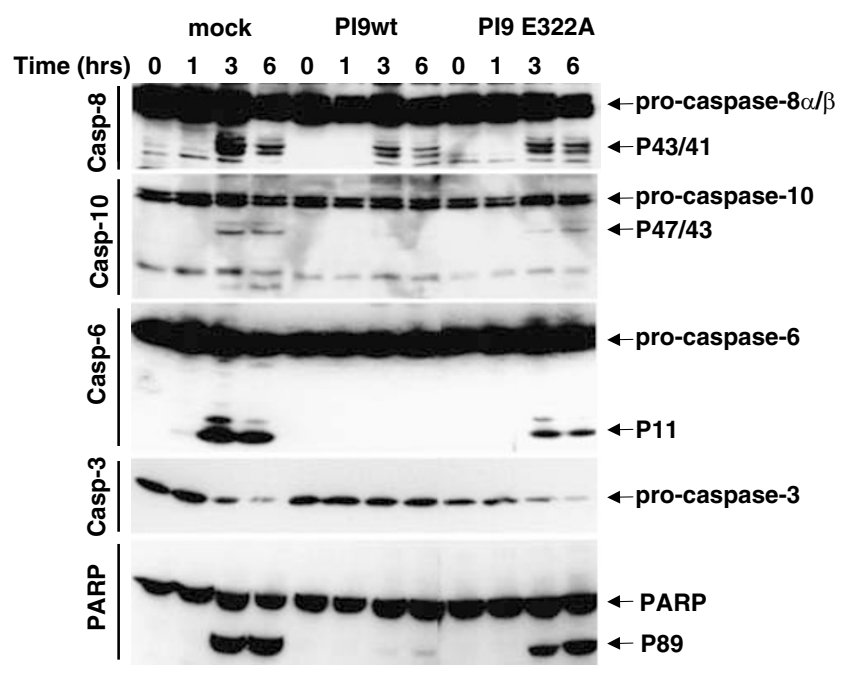

Figure 2 PI9 prevents caspase-3 and PARP but not caspase-8 processing. HT1080-I- $\kappa$ B, stably transformed with PI9wt, PI9 E322A or an empty viral vector (mock), were stimulated with $1 \mu \mathrm{g} / \mathrm{ml}$ TRAIL for the indicated time. At the time point $t=0$, TRAIL was added after lysis. The cell lysates were analyzed by Western blot for the processing of caspase-10, $-8,-6,-3$ and PARP 


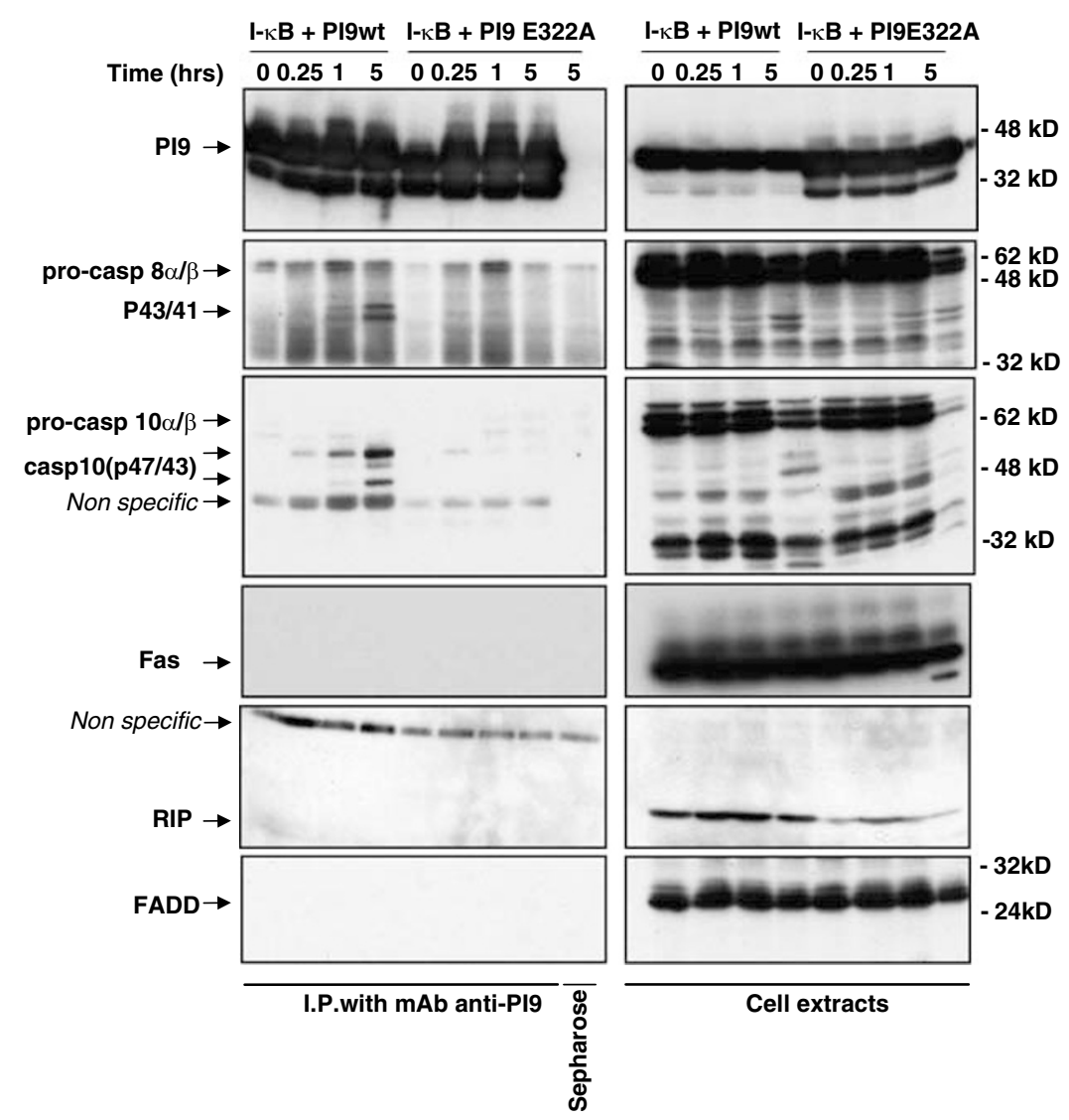

Figure 3 PI9 but not its $\mathrm{P}_{1}$ mutant binds active caspase-8 and -10 during FasL-mediated apoptosis. Right panel: HT1080-I- $\kappa \mathrm{B}$ stably transformed with PI9wt or PI9 E322A were stimulated with $2 \mu \mathrm{g} / \mathrm{ml} \mathrm{FasL}$ for the indicated time. At $t=0$ FasL was added after lysis. Cell lysates were analyzed by Western blot for the presence and/or processing of PI9, caspase-8, -10, Fas, RIP and FADD. Left panel: After FasL stimulation for the indicated time period, cells were lysed and immunoprecipitation was performed using a mAb against PI9. Immunoprecipitates were analyzed by Western blot in the same way as for the lysates

by inadequate PI9 expression, as PI9 protein levels were at least comparable to that of WEHI 164-PI9wt cells, although the expression level was lower compared to the HT1080-I$\kappa \mathrm{B}-\mathrm{PI}^{\mathrm{w} \mathrm{w}^{\text {low }}}$ (Figure $5 \mathrm{~b}$, inset).

We then investigated whether the presence of PI9 influences the DISC composition and if differences were found between sensitive and resistant cell lines. DISC formation was first analyzed in FasL-treated mock, PI9 E322A and PI9wt expressing HT1080-I- $\kappa$ B (Figure 6a). Rapid recruitment of FADD and pro-caspase-8 as well as partial processing of pro-caspase- 8 into its intermediate p43/41 fragment was observed in all transfectants with no obvious impact of PI9 expression on DISC composition. Similar results were obtained in Jurkat cells, in which PI9 overexpression did not affect DISC composition (Figure 6b). However, we detected obvious differences in the composition of the PI9 complex. Indeed, although a PI9/caspase-8 complex was readily immunoprecipitated from $\mathrm{HT} 1080-\mathrm{I}-\kappa \mathrm{B}$ cells (Figures 3 and $6 \mathrm{c}$ ), no p41/43 caspase-8 was co-immunoprecipitated in Jurkat cells (Figure 6c). Again, no interaction between PI9 and Fas or FADD was observed in Jurkat cells (data not shown), suggesting that the PI9-caspase-8 complex is not associated to the DISC.

\section{Discussion}

Several intracellular serpins, such as PAI-2, SCCA and CrmA, have been described to modulate cell death induced by members of the TNF family. ${ }^{8,9,23-25}$ In this report, we show that PI9 is also an inhibitor of TNF-, TRAIL- and FasLmediated apoptosis in certain TNF-sensitive tumor cell lines.

Figure 4 Dose-dependence between PI9 antigen levels and protection against TNF- and FasL-mediated cell death. The HT1080-I- $\kappa$ B-PI9wt ${ }^{\text {low }},-$ PI9wt ${ }^{\text {interm }},-$ PI9wt ${ }^{\text {high }}$, PIg $9^{\text {puro }}$ and -PI9 E322A high were all tested in triplicate for their sensitivity to FasL and TNF. (a) The result for a fixed concentration of FasL (125 ng/ml, left graph) and TNF $(625 \mathrm{ng} / \mathrm{ml}$, right graph). At the $\mathrm{x}$-axis, the PI9 protein concentration of the different clones is given (nanogram PI9 per milligram cellular protein). At the bottom, the mean percentage protection for each cell line compared to the control cells (PI9 E322 A $\left.{ }^{\text {high }}\right)$ is calculated. *Indicates statistically significant $(P<0,05)$ protection as compared to the control cells as analyzed by one-way ANOVA. (b-g) Slides of tonsil tissues injected with HT1080-I- $\kappa$ B-PI9wt ${ }^{\text {low }}(5 \mathrm{~B}),-\mathrm{PI} / \mathrm{wt}^{\text {interm }}(5 \mathrm{C})$ or PI9wt ${ }^{\text {high }}(5 \mathrm{D})$, and PI9wt ${ }^{\text {puro }}(5 \mathrm{E})$ were stained for PI9 and developed for $30 \mathrm{~s}$ with DAB. The PI9 expression by the tumor cells (arrows) was compared with endogenous PI9 expression by endothelial cells ( $5 \mathrm{~F}$, arrowhead) and dendritic cells (5G, arrowhead) present in the same tonsil $(400 \times)$ 

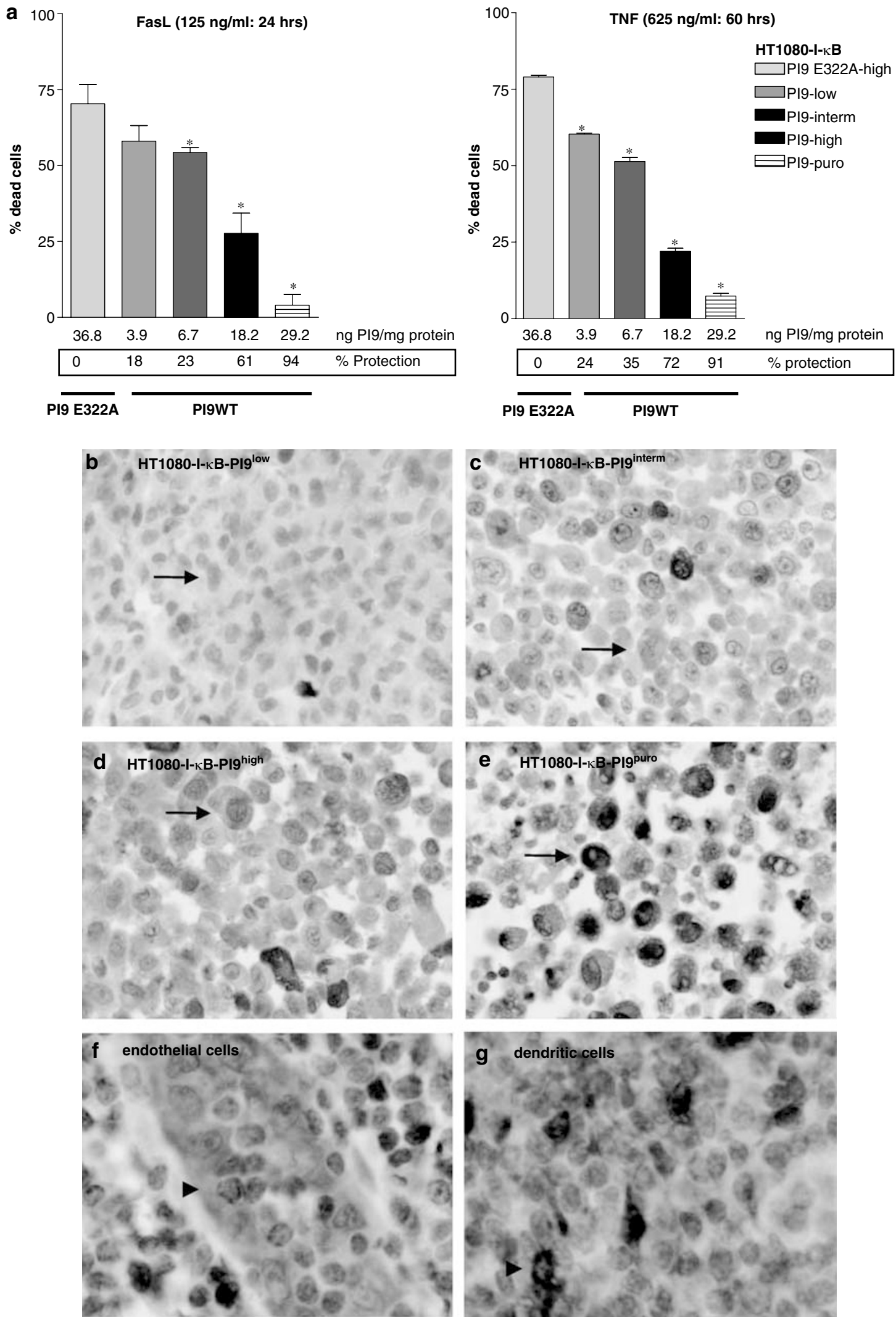


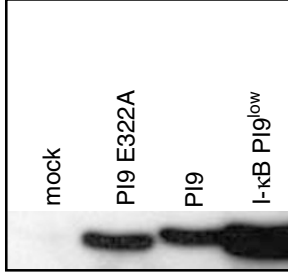

a

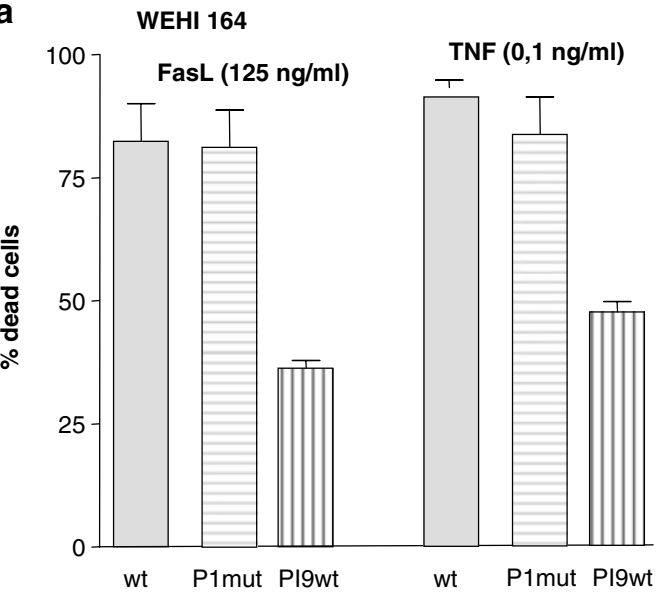

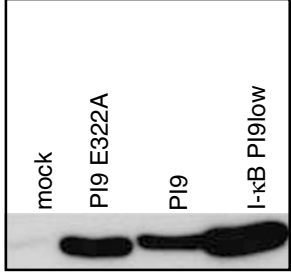

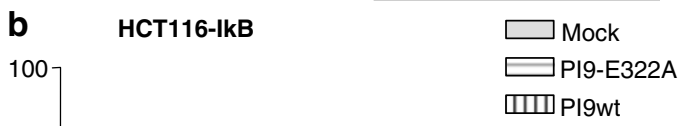

TNF (500 ng/ml)

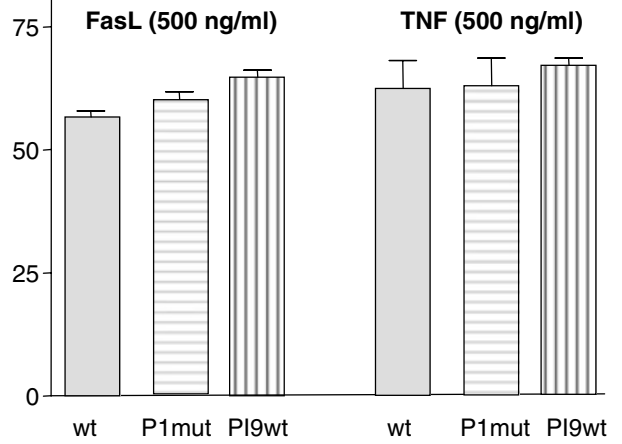

C

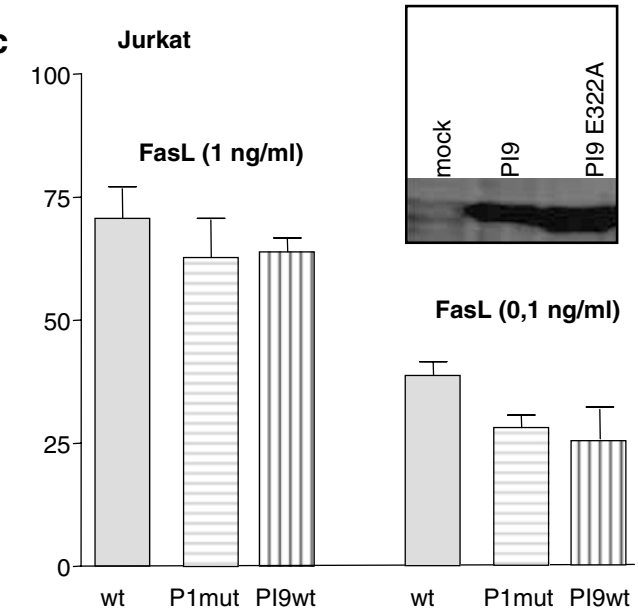

Figure 5 PI9 protects and (c) the Jurkat cell line WEHI 164 but not HCT116-I- -kBmut from TNF- and FasL-mediated apoptosis. (a) The WEHI 164 fibrosarcoma cell line, (b) the HCT116-I- $k$ Bmut colon carcinoma cell line and (c) the Jurkat cell line were infected with an empty vector (mock) or vectors containing PI9wt or PI9 E322A. After selection with puromycin, stably transformed cell populations were tested for protein expression by Western blot (see inset). Cell lines were treated with the indicated concentration of soluble forms of TNF or FasL

During ligand-mediated apoptosis, PI9 interacts with the intermediate active forms of caspase-8 (p43/41) and of caspase-10 (p47/43) during the apoptotic signal, preventing downstream caspase activation and cell death.

Activation of caspase- 8 and -10 mediated by Fas- or TRAIL receptors requires several distinct steps. The initial cleavage occurs after Asp-374, giving rise to the p43/p41 (and p47/43 in the case of caspase-10) and the p12 subunits. Two subsequent cleavages at Asp-216 and Asp-384 generate the p18 $(\alpha)$ and $p 10(\beta)$ subunits of the active enzyme. ${ }^{1}$ Activated caspase- 8 is released from the DISC to initiate the execution cascade leading to the activation of caspase-3, PARP cleavage and apoptosis. As expected, pro-caspase-8 and -10 as well as the intermediate active caspase- 8 ( $p 43 / 41)$ and -10 (p47/43) were significantly consumed in the sensitive cell lines, after $5 \mathrm{~h}$ of TRAIL or FasL stimulation (Figures 2 and 3). However, in the PI9wt expressing cells, downstream caspases and PARP were not cleaved, although procaspase8 and -10 were still processed into the intermediate active forms. These observations point to a PI9-mediated impairment of caspase- 8 and -10 processing. After the first processing step, the caspase- 8 (p43/p41) intermediate is still bound to the DISC via its DED domain and FADD. The second processing step cleaves the protein between the DED and the caspase unit resulting in the release of the active $p 18 / p 10$ heterotetramer into the cytoplasm (Figure 7a). Recent studies 
a
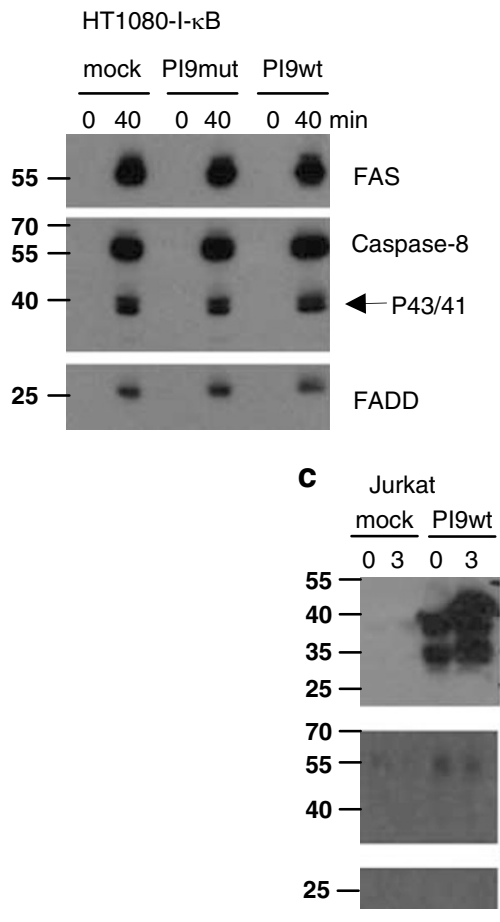

b $\mathrm{HT} 1080$

$-1 \kappa B \quad$ Jurkat
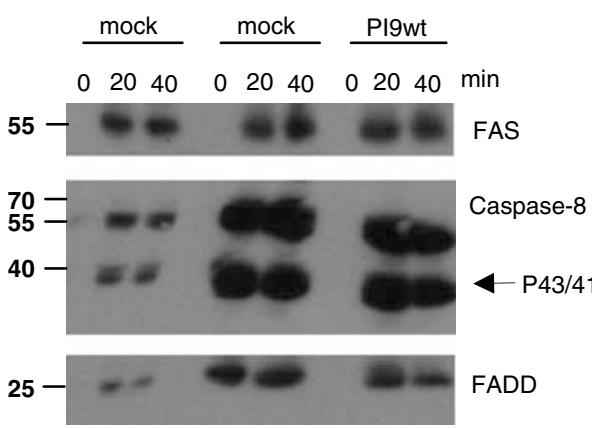

HT1080-IkB

PI9wt

$03 \mathrm{~h}$
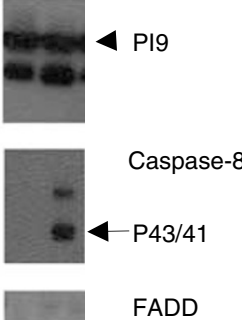

Figure 6 PI9 binds to active caspase-8 in HT1080 but not in Jurkat cells. (a) Western blot of DISCs (IP) of HT1080-I-kB stably transformed with empty (mock) vector, PI9 E322A and PI9wt. Cells were stimulated for 0 or 40 min with $2 \mu \mathrm{g} / \mathrm{ml}$ of FLAG-tagged FasL, which, after cell lysis, was immunoprecipitated using the anti-FLAG M2 antibody. In time point 0 , FasL was added after lysis. The DISCs were analyzed for the presence of Fas, FADD and caspase-8. (b) Jurkat (JA3) cells stably transformed with empty vector or PI9wt were stimulated for 0,20 and 40 min with FasL, and DISC analysis was performed as described above. (c) Jurkat and HT1080-I-kB stably transformed with empty vector (mock) or PI9wt were stimulated with $2 \mu \mathrm{g} / \mathrm{ml} \mathrm{FasL} \mathrm{for} 3 \mathrm{~h}$. At $t=0$, FasL was added after lysis. After FasL stimulation, cells were lysed and immunoprecipitation was performed using a mAb against PI9. Immunoprecipitates were analyzed by Western blot for the presence of PI9, caspase-8 and FADD

have provided insight into the molecular mechanism by which FLIP blocks apoptotic death. Like PI9, FLIP $\mathrm{L}_{\mathrm{L}}$ allows the first cleavage step of procaspases- 8 to occur, leading to the generation of the $\mathrm{p} 10$ subunit, but prevents further processing of the p43/p41subunits. ${ }^{26,27}$ Immunoprecipitation experiments of FLIP from FasL-treated HT1080wt cells demonstrated the co-precipitation of the p43/41fragment of caspase8 as well as FADD and Fas, ${ }^{26}$ indicating that FLIP and caspase-8 $43 / 41$ fragments interact and are both present in the DISC. However, in contrast to FLIP, no association of the PI9-p43/41 complex with proteins present in the DISC, such as FADD or Fas was observed (Figures 3 and $6 \mathrm{c}$ ). This suggests that the PI9-bound p43/p41 is cytosolic. A possible explanation for this detachment of PI9-p43/41 from the DISC may be that serpins undergo a major conformational change upon interaction with their target protease, the latter being moved to the opposite pole of the serpin, leading to disruption of the catalytic site. ${ }^{28}$ It is possible that this conformational change of PI9 disturbs the homotypic interaction of the DED domains of caspase- 8 or -10 with that of FADD in the DISC, releasing the complex into the cytosol (Figure $7 \mathrm{~b}$ ). Release of serpin-protease complexes from multi-molecular protein complexes has been described earlier. For example, $\mathrm{C} 1 \mathrm{rC} 1 \mathrm{~s}-\mathrm{C} 1$ inhibitor complexes are released from the $\mathrm{C} 1$ complement complex after activation and inhibition of $\mathrm{C} 1 \mathrm{r}$ and C1s. ${ }^{29}$
On itself the inhibition of caspase-8 by PI9 could already explain the anti-apoptotic effect of PI9. Our experiments, however, also showed a very early interaction between PI9 and the intermediate form of caspase-10. Recent studies have shown that caspase-10 is recruited to the native TRAIL and FasL DISC, whereas the protease is cleaved in a FADDdependent manner. ${ }^{30}$ Caspase- 10 is also recruited into TNFR1 complex II upon TNF stimulation. ${ }^{17}$ Nonetheless, the importance of caspase-10 in death receptor-induced apoptosis is still a matter of debate. Certain studies have shown that PI9 may also interact with caspase- 1 and thereby interfere with the release of IL-1 $\beta .{ }^{14,15}$ Although HT1080 cells have been described to secrete IL-1 $\beta$ we did not observe an enhanced IL-1 $\beta$ release after $24 \mathrm{~h}$ FasL stimulation (data not shown), thereby excluding a role of caspase- 1 activation in our system.

Our results point to a role of PI9 in the modulation of death receptor-mediated apoptosis in the fibrosarcoma cell lines HT1080 and WEHI-164, but not in other tumor cell lines tested (HCT116-I- $\kappa$ Bmut, MCF-7-I- $\kappa$ Bmut and Jurkat). An explanation for these differences could be that the viral transduction leads to high, non-physiological PI9 levels in certain cell lines. However, we have observed a good inhibition of death receptor-induced cell death with PI9 expression levels comparable to that naturally found in endothelial or dendritic cells. Apparently, the modulation of PI9 in death receptor- 
a

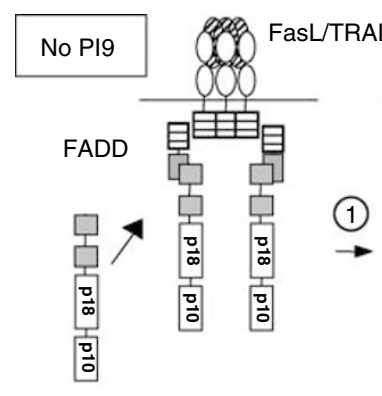

caspase-8

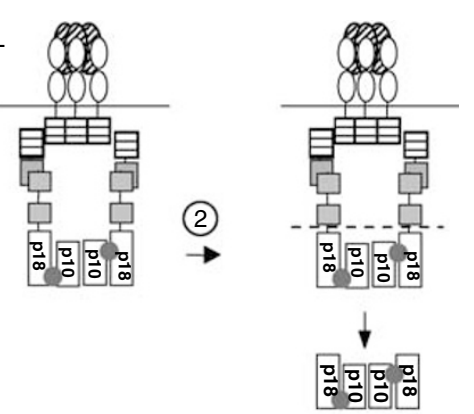

Cleavage of cytoplasmic substrates

APOPTOSIS

b

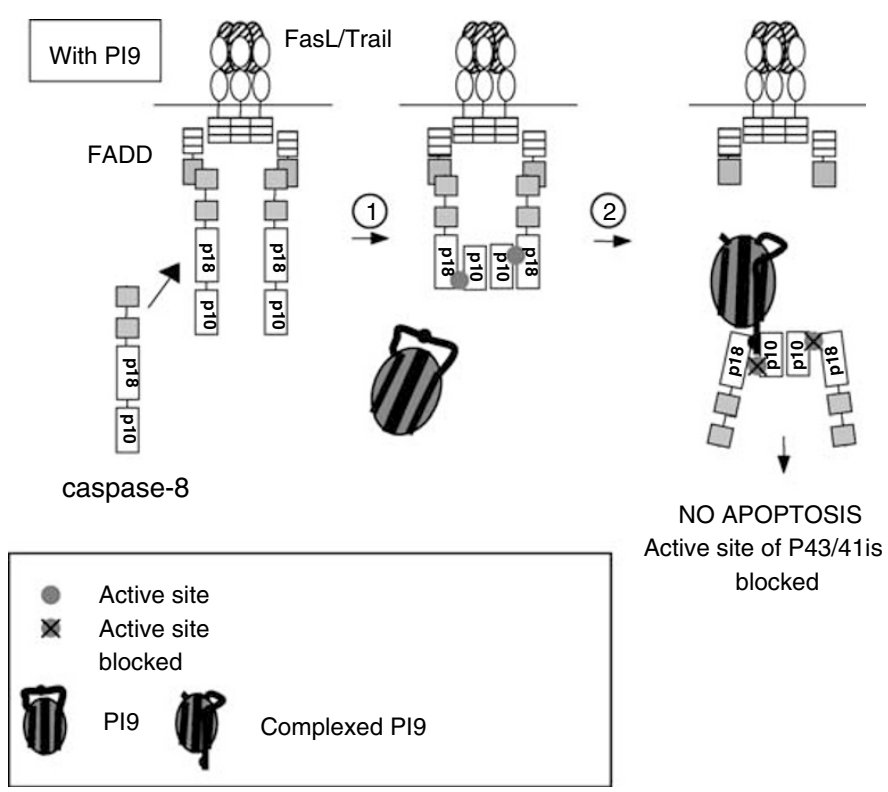

Figure 7 Proposed mechanism of modulation of FasL-TRAIL-mediated apoptotic death by PI9. See Discussion for details

mediated apoptosis is cell-type dependent and seems to be restricted to at least fibrosarcoma cell lines. In this context, we have observed that PI9-positive tumor cells were present in the majority of (fibro)sarcoma biopsies tested (18/23 cases) (unpublished data).

Why PI9 actions are cell-type dependent remains unclear. Our experiments show that PI9 binds to the active caspase-8 p43/41 fragments in HT1080 but not in Jurkat cells, suggesting that PI9 has no proper access to the active p41/43 subunits present in the DISC or in the cytoplasm of the latter cells. This was apparently not caused by distinct subcellular localization of PI9 in sensitive and resistant cells, as confocal imaging did not reveal differences under normal or FasLtreated conditions (data not shown). Why PI9 fails to interact with caspase-8 in non-protected cells is presently unsettled and requires further studies.

In order to assess whether reduction of endogenous levels of PI9 would sensitize cells to TNF- and FasL-mediated apoptosis, we attempted to knockdown PI9 by RNA inter- ference in certain cell lines that endogenously express PI9, such as the colon carcinoma cell line HCT8. Although knockdown of cFLIP in these cells increased sensitivity to TNF and FasL, only a small but nonsignificant increase of sensitivity was observed after knockdown of PI9 (results not shown). However, we have been unable to reduce the level of PI9 protein more than $50 \%$ with this technique. It is therefore possible that residual PI9 expression was still sufficient to block death pathways or that CFLIP or other anti-apoptotic factors compensated for PI9 deficiency.

Currently, it is thought that the physiological function of PI9 is to protect $C L$ against endogenous granzyme $B .{ }^{13}$ However, PI9 is also highly expressed in cells that do not express granzyme B, such as dendritic cells, cells at immune privileged sites (placenta, testis, ovary and eye) and endothelial cells. ${ }^{20}$ Tumors can express PI9 as well, for example various types of lymphomas, ${ }^{31}$ carcinoma, ${ }^{32,33}$ melanoma ${ }^{33,34}$ and sarcoma (unpublished data). In lymphoma and melanoma, PI9 overexpression correlates strongly 
with both grade and poor clinical outcome. ${ }^{31,34,35}$ Interestingly, cells from which the above-mentioned tumors originate (melanocytes, epithelial cells, supportive tissue) do not express endogenous $\mathrm{PI},{ }^{20}$ indicating that $\mathrm{PI} 9$ expression is upregulated during the malignant transformation. Besides inhibition of $\mathrm{GrB}$, our findings indicate another mechanism by which PI9 may protect tumor cells from the immune response. This may have implications for immunotherapies based on these death receptor ligands.

\section{Materials and Methods}

Cell culture. The human fibrosarcoma cell line HT1080 and its derivatives expressing $\mathrm{l}-\kappa \mathrm{B}$ mut or FLIP have been described previously $\mathrm{y}^{36,17}$ and were cultured in DMEM (Gibco, Life Technologies, Gaithersburg, MD, USA). The modified, TNFsensitive, colon carcinoma cell line HCT116-I- $\kappa$ Bmut was a kind gift from Dr. Y Deng (Huffington Center on Aging and Department of Molecular and Cellular Biology, Baylor College of Medicine, Houston, TX, USA) and was cultured in McCoy's 5A medium (Invitrogen/Gibco, Breda, NL, USA). ${ }^{21}$ Jurkat (JA3) and the modified, TNFsensitive, breast cancer cell line MCF-7-I- $\kappa$ Bmut (a kind gift from Dr. V Bours, Laboratory of Medical Chemistry and Human Genetics, Liege, Belgium) ${ }^{22}$ were cultured in RPMI 1640 and grown in $5 \% \mathrm{CO}_{2}$ at $37^{\circ} \mathrm{C}$. The TNF-sensitive murine fibrosarcoma cell line WEHI 164 was cultured in Iscove's modified Dulbecco's medium, $4.5 \mathrm{~g} / \mathrm{l} \mathrm{D}$-glucose. All media were supplemented with $10 \%$ fetal calf serum and penicillin/streptomycin ( $50 \mu \mathrm{g} / \mathrm{ml}$ of each). After isolation, HUVEC cells $\left(1 \times 10^{5}\right.$ cells $/ \mathrm{ml}$ ) were cultured in EGM-2 medium (BulletKit, \#CC-3162, Cambrex, Walkersville, MA, USA) in fibronectin-coated $(0.5 \mu \mathrm{g} / \mathrm{ml})$ culture flasks. They were grown for two passages until confluence and then again cultured for 24 and $48 \mathrm{~h}$ in triplicate for our experiments.

Antibodies and reagents. mAb Pl9-17 was described previously. ${ }^{20}$ Mouse mAb PI9-101 (IgG1) directed against human PI9 is a novel antibody raised against soluble recombinant human PI9 produced in yeast (a kind gift from Dr. W Kisiel, Department of Pathology, University of New Mexico School of Medicine, Albuquerque, NM, USA) and cross-reaction for other homologous serpins (PI6 PI8 and PAI-2) was excluded in a similar way as described previously for other intracellular serpins. ${ }^{19}$ Protein A-purified PI9-101 was coupled to CNBr-Sepharose4B. The following mouse $m A b s$ were used: anti-caspase-4 (Tx, IgG1), anti-caspase$8(5 \mathrm{~F} 7, \lg \mathrm{G} 2 \mathrm{~b})$ and anti-caspase-10 (4C1, lgG1) were obtained from MBL (Nagoya Japan); anti-caspase-3 (clone 19, IgG2a), anti-FADD (IgG1) and anti-RIP1 (clone 38, IgG2a) were from Transduction laboratories (Lexington, KY, USA); anticaspase-6 (clone B93-4, IgG1) was from Pharmingen (San Diego, CA, USA); and anti-FLAG (M2) antibody was purchased from Sigma. Rat mAb anti-FLIP (Dave II) was from Apotech (Lausen, Switzerland). The following rabbit polyclonal antibodies were used: against PARP (Biolabs, Beverly, MA, USA) and Fas (Santa Cruz C20). zVAD-fmk and soluble recombinant Flag-tagged forms of human super-FasL, TRAIL and TNF were purchased from Apotech Co. (Lausen, Switzerland).

Plasmids, cloning and site-directed mutagenesis. Human flagtagged FLIP $P_{L}$ in pMSCV puro was described previously. ${ }^{36}$ The point mutation of the P1-residue $(G A G=$ Glu322 $\rightarrow C T C=$ Ala322 $)$ in the reactive site loop of PI9 was introduced by PCR method using the full-length human PI9 CDNA as a template. ${ }^{3}$ The PI9wt and PI9 E322A constructs were amplified with a Kozak sequence (GCC ACC) in front of the ATG and were flanked with BamHI and Xhol sites. The PCR product was cloned into the plasmid pCR-Blunt (Invitrogen), sequenced on both strands and subcloned as BamHI/Xhol fragments into the retroviral vector pMSCVpuro (Clonetech) and into MSCV-IRES-eGFP (a kind gift by WS Pear, Department of Pathology and Institute for Medicine and Engineering, University of Pennsylvania, Philadelphia, PA, USA). ${ }^{37}$

Retrovirus production and cell transduction. Retroviruses and stable cell populations were produced essentially as described previously. ${ }^{38}$ Briefly, 293T cells were transiently transfected with pMSCVpuro (mock), pMSCVpuro-FLIP pMSCVpuro-PI9wt, pMSCVpuro-PI9 E322A, MSCV-IRES-eGFP, MSCV-PI9wtIRES-eGFP and MSCV-PI9 E322A-IRES-eGFP, and co-transfected with the pHIT60 and VSV-G plasmids, containing the sequences for gag-pol and VSV-G, respectively. The cell lines HT1080wt, HT1080-I- $\kappa$ Bmut, WEHI 164, MCF7-I- $\kappa$ Bmut and $\mathrm{HCT} 116-\mathrm{I}-\kappa \mathrm{Bmut}$ were first pre-incubated with polybrene $(8 \mu \mathrm{g} / \mathrm{ml})$ during
$20 \mathrm{~min}$ at $37^{\circ} \mathrm{C}$. Then cells were incubated four times $2 \mathrm{~h}$ with the viral supernatant at $37^{\circ} \mathrm{C}$. In case of THP-1, cells were first centrifuged in the presence of the virus during $30 \mathrm{~min}$ at 1000 r.p.m. and then incubated for $1.5 \mathrm{~h}$. Cells were washed in phosphate-buffered saline (PBS) and incubated in complete medium. The following day, puromycin $(2.5 \mu \mathrm{g} / \mathrm{ml})$ was added to the medium for at least 3 days and for 2 weeks in the case of THP-1. Five days after infection, the MSCV-PI9wt-IRES-eGFP and MSCV-PI9 E322A-IRES-eGFP transformed HT1080-I- $\kappa$ Bmut cells were sorted for eGFP expression resulting in cell populations expressing low (PI9wt ${ }^{\text {low }}$ PI9

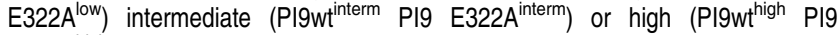
E322A ${ }^{\text {high }}$ ) PI9 protein levels. Thereafter, cells were amplified, tested for PI9 protein expression (see below) and used for the cytotoxicity experiments.

Cell death and viability assays. The cell lines or transfectants derived thereof were harvested, washed and seeded in 96-well flat bottom microtiter plates at a density of $10^{4}$ per well. Cells were incubated in the presence of increasing concentrations of super-FasL ( $24 \mathrm{~h}$ ), TRAIL ( $24 \mathrm{~h}$ ) and TNF (24, 48 and $60 \mathrm{~h}$ ), after which time the cell viability was determined with the PMS/MTS assay (Jurkat) or with the methylene blue colorimetric assay (adherent cells). In the case of TRAlL, $1 \mu \mathrm{g} /$ $\mathrm{ml}$ of cross-linking anti-FLAG (M2) antibody was added. Experiments were repeated at least five times.

Preparation of cell lysates and Western blotting. Cell lysates were prepared in lysis buffer (20 mM Tris- $\mathrm{HCl}$ pH 7.4, $150 \mathrm{mM} \mathrm{NaCl}, 10 \%$ glycerol, $0.1 \%$ Nonidet P-40) supplemented (except during the immunoprecipitation of PI9) with a protease inhibitor cocktail (Roche Biochemicals, Basel, Switzerland). Cell debris and nuclei were removed by centrifugation at $10000 \times g$ for $10 \mathrm{~min}$ and protein concentration was determined by the Bradford assay (Pierce, Rockford, IL, USA). Proteins were resolved by SDS-PAGE and transferred onto nitrocellulose membranes by electroblotting and nonspecific binding sites were blocked by incubation in Tris-buffered saline, $0.5 \%$ Tween- 20 and $5 \%$ (w/v) dry milk. Western blot analyses were performed with the indicated antibodies. Bound primary antibodies were visualized with horseradish peroxidase-conjugated goat anti-rabbitIgG, goat anti-rat-IgG or goat anti-mouse-IgG (Jackson Immunoresearch Laboratories, West Grove, PA, USA) and ECL (Amersham, Freiburg, Germany). For the detection of various caspases after PI9 immunoprecipitation analysis, the subclass-specific, horseradish peroxidase-conjugated, goat anti-mouse $\lg G 1$, $\lg \mathrm{G} 2 \mathrm{a}$ and IgG2b from Southern Biotechnology Associates (Birmingham, AL, USA) were used.

PI9 immunoprecipitation and DISC analysis. HT1080-I- $\kappa$ Bmut-PI9wt, HT1080-I- $\kappa$ Bmut-PI9 E322A (after detachment), Jurkat-PI9wt and mock-infected Jurkat cells were washed twice with complete medium and counted. For experiments, $2 \times 10^{7}$ cells per time point were resuspended in $2 \mathrm{ml}$ in a $15 \mathrm{ml}$ tube. Cells were stimulated for $0 \mathrm{~min}, 15 \mathrm{~min}, 1 \mathrm{~h}$ and $5 \mathrm{~h}$ at $37^{\circ} \mathrm{C}$ in the presence of $2 \mu \mathrm{g} / \mathrm{ml}$ of super-FasL. The tubes were shaken every $15 \mathrm{~min}$. The reaction was terminated by adding ice-cold PBS and by washing them twice at $4^{\circ} \mathrm{C}$ with ice-cold PBS. Then cells were lysed in $500 \mu$ l lysis buffer as described under 'Preparation of cell lysate', in the absence of protease inhibitors. The lysates were precleared with $20 \mu \mathrm{l}$ Sepharose-6 B (Sigma-Aldrich) for $1 \mathrm{~h}$ at $4^{\circ} \mathrm{C}$. For PI9 immunoprecipitation, lysates were incubated with $30 \mu \mathrm{l}$ of mAb PI9-101-Sepharose beads (pre-washed $4 \times$ with ice-cold lysis buffer) and for DISC analysis lysates were incubated with $30 \mu \mathrm{l}$ of protein A-agarose. After $4 \mathrm{~h}$ incubation at $4^{\circ} \mathrm{C}$, beads were recovered by centrifugation, washed four times with $500 \mu$ lice-cold lysis buffer and resuspended in non-reducing sample buffer before analysis by SDS-PAGE and Western blotting.

PI9 ELISA. The PI9 ELISA was performed essentially as described previously. ${ }^{19}$ A rabbit polyclonal anti-PI9 antibody $(1 \mu \mathrm{g} / \mathrm{ml})$ was used for coating microtiter plates, and biotinylated mAb PI9-101 (about $5 \mu \mathrm{g} / \mathrm{ml}$ ) for detection. Recombinant human PI9 produced in yeast served as a standard.

Immunohistochemistry. Five million of $\mathrm{HT} 1080-\mathrm{I}-\kappa$ Bmut-PI9wt-IRES-eGFP expressing low, intermediate or high levels of PI9 were injected into human tonsils, obtained from our department of ENT surgery after standard tonsillectomy. After injection, the tonsils were directly processed by fixation in $10 \%$ buffered formalin for $18 \mathrm{~h}$ and subsequently embedded in paraffin. Three- $\mu \mathrm{m}$ thick sections of the sarcoma biopsies and the injected tonsils were mounted on poly-L-lysine-coated slides and stained for PI9, using the mAb PI9-17 (at $2.5 \mu \mathrm{g} / \mathrm{ml}$ ), exactly as described previously. ${ }^{31}$ Briefly, bound antibodies were detected with biotinylated rabbit-antimouse $\mathrm{Fab}_{2}$ immunoglobulin and streptavidin-biotin-horseradish peroxidase 
complex (sABC, DAKO A/S, Glostrup, Denmark) and visualized by incubation with $\mathrm{DAB}\left(0.1 \mathrm{mg} / \mathrm{ml}, 0.02 \% \mathrm{H}_{2} \mathrm{O}_{2}\right)$ for $30 \mathrm{~s}$. Slides were counterstained with hematoxylin and mounted.

Acknowledgements. This work was supported by a travel grant and a project grant (UU 2004-3047) from the Dutch Cancer Foundation (to JAK) and by grants from the Swiss National Research Fondation (to JT). We thank Dr. Y Deng (Huffington Center on Aging and Department of Molecular and Cellular Biology, Baylor College of Medicine, Houston, TX, USA) for the HCT116-I- $\kappa$ Bmut cell line, Dr. V Bours (Laboratory of Medical Chemistry and Human Genetics, Liege, Belgium) for the MCF-7-I- $\kappa$ Bmut cell line, Angela Kamp, Dorien Wouters and Bellinda Bladergroen for help with the production and characterization of the $\mathrm{mAb}$ PI9-101 and the members of the whole Tschopp group for their technical support and stimulating discussions.

1. Shi Y. Mechanisms of caspase activation and inhibition during apoptosis. Mol Cell 2002; 9 : 459-470.

2. Lieberman J. The ABCs of granule-mediated cytotoxicity: new weapons in the arsenal. Nat Rev Immunol 2003; 3: 361-370.

3. Lowin B, Hahne M, Mattmann C, Tschopp J. Cytolytic T-cell cytotoxicity is mediated through perforin and Fas lytic pathways. Nature 1994; 370: 650-652.

4. Locksley RM, Killeen N, Lenardo MJ. The TNF and TNF receptor superfamilies: intergrating mammalian biology. Cell 2001; 104: 487-501.

5. Chinnaiyan AM, O'Rourke K, Tewari M, Dixit VM. FADD, a novel death domain-containing protein, interacts with the death domain of Fas and initiates apoptosis. Cell 1995; 81: 505512.

6. Schneider P, Thome M, Burns K, Bodmer JL, Hofmann K, Kataoka T et al. TRAlL receptors 1 (DR4) and 2 (DR5) signal FADD-dependent apoptosis and activate NF-kappaB. Immunity 1997; 7: 831-836.

7. Irmler M, Thome M, Hahne M, Schneider P, Hofmann $\mathrm{K}$, Steiner V et al. Inhibition of death receptor signals by cellular FLIP. Nature 1997; 388: 190-195.

8. Zhou Q, Snipas S, Orth K, Muzio M, Dixit VM, Salvesen GS. Target protease specificity of the viral serpin CrmA. Analysis of five caspases. J Biol Chem 1997; 272: 7797-7800.

9. Tewari M, Dixit VM. Fas- and tumor necrosis factor-induced apoptosis is inhibited by the poxvirus crmA gene product. J Biol Chem 1995; 270: 3255-3260.

10. Bird PI. Serpins and regulation of cell death. Results Probl Cell Differ 1998; 24: 63-89.

11. Sprecher CA, Morgenstern KA, Mathewes S, Dahlen JR, Schrader SK, Foster DC et al. Molecular cloning, expression, and partial characterization of two novel members of the ovalbumin family of serine proteinase inhibitors. J Biol Chem 1995; 270: 29854-29861.

12. Bird CH, Sutton VR, Sun J, Hirst CE, Novak A, Kumar $S$ et al. Selective regulation of apoptosis: the cytotoxic lymphocyte serpin proteinase inhibitor 9 protects against granzyme B-mediated apoptosis without perturbing the Fas cell death pathway. Mol Cell Biol 1998; 18: 6387-6398.

13. Zhang M, Park SM, Wang Y, Shah R, Liu N, Murmann AE et al. Serine protease inhibitor 6 protects cytotoxic $T$ cells from self-inflicted injury by ensuring the integrity of cytotoxic granules. Immunity 2006; 24: 451-461.

14. Annand RR, Dahlen JR, Sprecher CA, De Dreu P, Foster DC, Mankovich JA et al. Caspase-1 (interleukin-1beta-converting enzyme) is inhibited by the human serpin analogue proteinase inhibitor 9. Biochem J 1999; 342: 655-665.

15. Young JL, Sukhova GK, Foster D, Kisiel W, Libby P, Schonbeck U. The serpin proteinase inhibitor 9 is an endogenous inhibitor of interleukin 1beta-converting enzyme (caspase-1) activity in human vascular smooth muscle cells. J Exp Med 2000; 191: 1535-1544.

16. Bots M, VAN Bostelen L, Rademaker MT, Offringa R, Medema JP. Serpins prevent granzyme-induced death in a species-specific manner. Immunol Cell Biol 2006; 84: 79-86.

17. Micheau 0 , Tschopp J. Induction of TNF receptor I-mediated apoptosis via two sequential signaling complexes. Cell 2003; 114: 181-190.

18. Gettins PG. Serpin structure, mechanism, and function. Chem Rev 2002; 102: 4751-4804.
19. Bladergroen BA, Strik MC, Wolbink AM, Wouters D, Broekhuizen R, Kummer JA et al. The granzyme $B$ inhibitor proteinase inhibitor $9(\mathrm{PI} 9)$ is expressed by human mast cells. Eur $J$ Immunol 2005; 35: 1175-1183.

20. Bladergroen BA, Strik MC, Bovenschen N, van Berkum O, Scheffer GL, Meijer CJ et al. The granzyme $B$ inhibitor, protease inhibitor 9 , is mainly expressed by dendritic cells and at immune-privileged sites. J Immunol 2001; 166: 3218-3225.

21. Deng $Y$, Ren $X$, Yang L, Lin Y, Wu X. A JNK-dependent pathway is required for TNFalphainduced apoptosis. Cell 2003; 115: 61-70.

22. Benoit V, Chariot A, Delacroix L, Deregowski V, Jacobs N, Merville MP et al. Caspase-8dependent HER-2 cleavage in response to tumor necrosis factor alpha stimulation is counteracted by nuclear factor kappaB through c-FLIP-L expression. Cancer Res 2004; 64 2684-2691.

23. Dickinson JL, Bates EJ, Ferrante A, Antalis TM. Plasminogen activator inhibitor type 2 inhibits tumor necrosis factor alpha-induced apoptosis. Evidence for an alternate biological function. J Biol Chem 1995; 270: 27894-27904.

24. Schleef RR, Chuang TL. Protease inhibitor 10 inhibits tumor necrosis factor alpha-induced cell death. Evidence for the formation of intracellular high $M(r)$ protease inhibitor 10containing complexes. J Biol Chem 2000; 275: 26385-26389.

25. Suminami Y, Nagashima S, Vujanovic NL, Hirabayashi K, Kato H, Whiteside TL. Inhibition of apoptosis in human tumour cells by the tumour-associated serpin, SCC antigen-1. Br J Cancer 2000; 82: 981-989.

26. Micheau O, Thome M, Schneider P, Holler N, Tschopp J, Nicholson DW et al. The long form of FLIP is an activator of caspase-8 at the Fas death-inducing signaling complex. $J$ Biol Chem 2002; 277: 45162-45171.

27. Krueger A, Schmitz I, Baumann S, Krammer PH, Kirchhoff S. Cellular FLICE-inhibitory protein splice variants inhibit different steps of caspase-8 activation at the CD95 deathinducing signaling complex. J Biol Chem 2001; 276: 20633-20640.

28. Huntington JA, Read RJ, Carrell RW. Structure of a serpin-protease complex shows inhibition by deformation. Nature 2000; 407: 923-926.

29. Ziccardi RJ, Cooper NR. Active disassembly of the first complement component, C-1, by C1 inactivator. J Immunol 1979; 123: 788-792.

30. Sprick MR, Rieser E, Stahl H, Grosse-Wilde A, Weigand MA, Walczak H. Caspase-10 is recruited to and activated at the native TRAIL and CD95 death-inducing signalling complexes in a FADD-dependent manner but can not functionally substitute caspase-8. EMBO J 2002; 21: 4520-4530.

31. Bladergroen BA, Meijer CJ, ten Berge RL, Hack CE, Muris JJ, Dukers DF et al. Expression of the granzyme $B$ inhibitor, protease inhibitor 9 , by tumor cells in patients with non-Hodgkin and Hodgkin lymphoma: a novel protective mechanism for tumor cells to circumvent the immune system? Blood 2002; 99: 232-237.

32. Oudejans JJ, Harijadi H, Kummer JA, Tan IB, Bloemena E, Middeldorp JM et al. High numbers of granzyme $B / C D 8$-positive tumour-infiltrating lymphocytes in nasopharyngeal carcinoma biopsies predict rapid fatal outcome in patients treated with curative intent. $J$ Pathol 2002; 198: 468-475

33. Medema JP, de Jong J, Peltenburg LT, Verdegaal EM, Gorter A, Bres SA et al. Blockade of the granzyme B/perforin pathway through overexpression of the serine protease inhibitor PI-9/SPI-6 constitutes a mechanism for immune escape by tumors. Proc Natl Acad Sc USA 2001; 98: 11515-11520.

34. van Houdt IS, Oudejans JJ, van den Eertwegh AJ, Baars A, Vos W, Bladergroen BA et al. Expression of the apoptosis inhibitor protease inhibitor 9 predicts clinical outcome in vaccinated patients with stage III and IV melanoma. Clin Cancer Res 2005; 11: 6400-6407.

35. ten Berge RL, Meijer CJ, Dukers DF, Kummer JA, Bladergroen BA, Vos W et al. Expression levels of apoptosis-related proteins predict clinical outcome in anaplastic large cell lymphoma. Blood 2002; 99: 4540-4546.

36. Micheau O, Lens S, Gaide O, Alevizopoulos K, Tschopp J. NF-kappaB signals induce the expression of c-FLIP. Mol Cell Biol 2001; 21: 5299-5305.

37. Pear WS, Miller JP, Xu L, Pui JC, Soffer B, Quackenbush RC et al. Efficient and rapid induction of a chronic myelogenous leukemia-like myeloproliferative disease in mice receiving P210 bcrlabl-transduced bone marrow. Blood 1998; 92: 3780-3792.

38. Soneoka Y, Cannon PM, Ramsdale EE, Griffiths JC, Romano G, Kingsman SM et al. A transient three-plasmid expression system for the production of high titer retroviral vectors. Nucleic Acids Res 1995; 23: 628-633. 